\title{
Turismo: driver de crecimiento de las empresas de la industria turística en los municipios costeros del Golfo de Morrosquillo del Departamento de Sucre
}

\author{
Tourism: driver of growth for companies in the tourism industry in the coastal municipalities of the gulf of \\ Morrosquillo in the Department of Sucre
}

DOI: $10.21803 /$ adgnosis.v8i8.364

\section{Resumen}

El Turismo en el Golfo de Morrosquillo representa una importante y priorizada apuesta productiva del departamento de Sucre, su contribución a la economía cada vez es más significativa. Sin embargo, el desarrollo competitivo de las empresas ha sido un reto que afronta muchas limitaciones. La estructura de modelos donde se identifiquen las variables que dinamizan la industria turística es la herramienta para potencializar las riquezas de la región e incursionar hacia mercados de escala internacional. El principal propósito de este artículo es analizar las condiciones de las empresas turísticas del golfo de Morrosquillo teniendo en cuenta el modelo de competitividad de Crouch y Ritchie. Los resultados evidenciaron debilidades del sector, pero a la vez develo las oportunidades con el que cuenta el departamento de Sucre.

Palabras clave: Turismo, Competitividad, Modelos, Estrategias

\section{Abstract}

Tourism in the Gulf of Morrosquillo represents an important and prioritized productive bet of the department of Sucre, its contribution to the economy is increasingly significant. However, the competitive development of the companies has been a challenge that faces many limitations. The models structure that identifies the variables that dynamize the tourism industry is the tool to potentiate the region's wealth and to enter international markets. The main purpose of this article is to analyze the conditions of tourism enterprises in the Gulf of Morrosquillo, taking into account the Crouch and Ritchie model of competitiveness. The results showed weaknesses of the sector, however, at the same time revealed the opportunities that the department of Sucre possesses.

Keywords: Tourism, Competitiveness, Models, Strategies
Omar Valladares Icedo'
mbaomar@uabc.edu.mx

Angélica Aguirre Bertel ${ }^{2}$

angelicaaguirre@hotmail.com

Javier Prieto Flórez ${ }^{3}$

javierprietoflorez@gmail.com 


\section{Introducción}

Las exigencias del mercado y del entorno cada vez son mayores y sumergen a las empresas y a los sectores económicos en una realidad impulsada por la globalización, la diversificación de productos y servicios, y la conectividad a través de las tecnologías de información y comunicación. Adaptarse y responder inteligentemente ante los cambios es un reto que se debe afrontar con estrategias que permitan el robustecimiento y desarrollo de las competencias de las empresas, mediante el diseño de planes a corto y mediano plazo para favorecer el crecimiento de las regiones y naciones (Peinado, 2018; Rubio, 2018; Sarmiento, 2018; Vergara et al., 2019).

El sector turismo no es indiferente a esta situación, por el contrario, cada día se enfrenta a situaciones coyunturales que requieren de procesos cooperativos para fortalecer las ventajas comparativas del territorio y cumplir las expectativas del turista, mediante un recurso humano con competencias, lo que ayuda al fortalecimiento de la marca. Si a ello se suma los cambios en el comportamiento, exigencias de los turistas y aparición de nuevos segmentos, el incrementar el nivel de competitividad de las empresas se vuelve un reto más ambicioso, que se traduce en el fortalecimiento de muchos factores (Del Río Cortina y Santisteben Rojas, 2011; Del Rio-Cortina y Robledo-Fernández, 2014). Es por ello, que se hace imprescindible profundizar en el análisis de las variables explicativas de la competitividad que permitan respaldar las actividades de planificación y gestión turística a fin de jalonar la economía en el sector y beneficiar a las comunidades locales.

\section{Marco teórico}

El sector turismo es un gran dinamizador de la economía nacional, para ello es importante estudiar desde la competitividad hasta los modelos que marcan la guía para impulsar el desarrollo de los destinos. De este modo, se muestra una revisión bibliográfica que se aborda desde la conceptualización del turismo, pasando por la definición de competitividad turística hasta los diferentes modelos que propician el desarrollo en los destinos turísticos.

\section{Competitividad turística}

$\mathrm{Al}$ igual que con el concepto de turismo, antes de abordar los modelos de desarrollo turístico. A continuación, se realiza una aproximación desde el concepto de competitividad turística.

Tabla 2.

\begin{tabular}{|c|c|}
\hline Autores & Competitividad turística \\
\hline Porter (1990) & $\begin{array}{l}\text { La competitividad de un destino tiene como objetivo principal } \\
\text { producir un alto y creciente nivel de vida para los ciudadanos, lo } \\
\text { cual, depende de la capacidad de utilizar los recursos y el capital de } \\
\text { trabajo. }\end{array}$ \\
\hline $\begin{array}{c}\text { Ritchie y Crouch } \\
\text { (2003) }\end{array}$ & $\begin{array}{l}\text { Un destino competitivo es aquel que promueve el máximo bienestar } \\
\text { para sus habitantes de forma sostenible. Además, contemplan que el } \\
\text { destino turístico debe ser sostenible no solo económicamente sino } \\
\text { también ecológica, social, cultural y políticamente para ser } \\
\text { verdaderamente competitivo. }\end{array}$ \\
\hline $\begin{array}{c}\text { Dwyer y Kim } \\
\text { (2003) }\end{array}$ & $\begin{array}{l}\text { La competitividad turística se mide por el incremento en los ingresos } \\
\text { reales de los ciudadanos bajo condiciones justas y de libre mercado, } \\
\text { que conlleven a un mejoramiento en el nivel de vida. }\end{array}$ \\
\hline Valls (2004) & $\begin{array}{l}\text { Para que un destino turístico sea competitivo debe generar a largo } \\
\text { plazo beneficios superiores a la media de la competencia en tres } \\
\text { ámbitos: beneficios económicos (mejores inversores, empresarios, } \\
\text { trabajadores, proveedores, expertos), beneficios sociales (calidad de } \\
\text { vida, puestos de trabajo de calidad, innovación) y beneficios } \\
\text { medioambientales (financiación de la tasa de regeneración). }\end{array}$ \\
\hline $\begin{array}{l}\text { Hassan (como se } \\
\text { citó en Flores } \\
\text { Ruiz, 2007) }\end{array}$ & $\begin{array}{l}\text { La competitividad como la capacidad del destino para crear e } \\
\text { integrar productos con valor añadido que proteja sus recursos y, al } \\
\text { tiempo, mantener su posición competitiva entre destinos } \\
\text { competidores. }\end{array}$ \\
\hline $\begin{array}{l}\text { Sánchez y } \\
\text { Fajardo (como se } \\
\text { citó en Diéguez } \\
\text { Castrillón et al., } \\
\text { 2011) }\end{array}$ & $\begin{array}{l}\text { La competitividad como un fenómeno muy complejo, comparativo, } \\
\text { dinámico, multidimensional y dificil de medir que no puede ser } \\
\text { observado directamente. Es tanta su complejidad, que existen } \\
\text { indicadores objetivos con variables como infraestructura, atractivos, } \\
\text { inversión; y a su vez indicadores subjetivos que se relacionan con la } \\
\text { percepción que manifiestan los grupos de interés hacia el destino. }\end{array}$ \\
\hline
\end{tabular}

Fuente: Elaboración propia.

a) Desde la perspectiva de muchos autores la competitividad de un destino turístico va de la mano con los factores que generan ventaja comparativa, las cuales inciden en la localización de las empresas turísticas y se localizan en el mismo territorio. Se pueden agrupar estos factores en tres grandes categorías (Palomeque, Marchena, Clavé \& Vera, 1997).

b) Factores espaciales: se refiere a la distancia física existente entre los principales núcleos emisores y los núcleos receptores del destino turístico.

c) Factores ambientales: indica las condiciones o atributos cuantitativos y cualitativos que confor- 
man el espacio geográfico de los destinos turísticos. Estos atributos se clasifican a su vez, en dos grandes grupos, los naturales clima, flora, fauna, abundancia de agua, y los culturales, patrimonio y costumbres heredadas de nuestros antepasados.

d) Factores dinámicos: son aquellos factores que pueden cambiar con el tiempo más fácilmente que los factores ambientales. Según postulados de Vera Rebollo, la localización turística está determinada por factores económicos como la política monetaria, la influencia del valor de las monedas y la sucesión de situaciones económicas coyunturales (inflación, crisis cíclicas) (Palomeque, Marchena, Clavé \& Vera, 1997, p.70).

La competitividad en un destino turístico debe contemplar desde la administración de los recursos naturales hasta la estrategia empleada por el sector empresarial (Del Rio-Cortina \& Blanquicett, 2009; Del Rio-Cortina \& Pérez Correa, 2009; Del Rio-Cortina, Sepúlveda Chaverra \& Meriño Stand, 2009) estos, articulados con el papel de los entes gubernamentales; puesto que la competitividad es un concepto que agrupa diferentes elementos, por lo que su medición además de ser relativa, es difícil de contabilizar. Muchos autores se han propuesto definir diferentes modelos que den explicación a la realidad en la gestión de los destinos, bien sea una explicación del comportamiento de arribos de turistas, o guías de actuación política/privada para dotar al destino de un mayor valor frente a la competencia. Cabe destacar entre los pioneros de un nuevo turismo vinculado a las Tics, Poon (1993) quien sugiere cuatro claves para jalonar destinos turísticos competitivos: (1) considerar en primer lugar el entorno para resaltar las ventajas comparativas; (2) convertir al turismo en la actividad principal; (3) fortalecer los canales de distribución; y por último (4) construir un sector privado dinámico.

\section{Modelos para el desarrollo de la competitivi- dad de destinos turísticos.}

Las exigencias del mercado y del entorno cada vez son mayores y las épocas de turbulencia sumergen a las empresas y a los sectores económicos en una realidad impulsada por la globalización, la diversificación de productos y servicios, y la conectividad a través de las tecnologías de información y comunicación. Adaptarse y responder inteligentemente ante los cambios es un reto que se debe afrontar con estrategias de crecimiento y estructurando modelos de gestión flexible. El sector turístico no es indiferente a esta situación, por el contrario, sus actividades y productos son asediados por su naturaleza y proyección a escala internacional.

En este orden de ideas, el modelo de desarrollo turístico de cada región, más que ser un referente potencial en la economía, debe considerar factores del entorno, claves para la conservación y la sostenibilidad, que conlleven a brindar a las comunidades garantías en la calidad de vida. De este modo, los factores y características del modelo turístico pueden ser entendidos a través de cuatro grandes fuerzas: consumidores, tecnología, producción y gestión; cada una de las cuales con implicaciones múltiples en su dimensión de análisis. Estas fuerzas están determinadas por un conjunto global y competitivo muy singular y único en la historia, en donde factores como flexibilidad, segmentación y preocupación medioambiental se han puesto como condicionantes del desarrollo turístico (Mazaro \& Varzin, 2008).

Modelo conceptual de la competitividad del destino de Crouch y Ritchie.

Con el modelo de Calgary, sus autores ofrecen un marco de referencia con la finalidad de ayudar al destino a competir de un modo más eficaz. Matizan que un destino turístico competitivo debe contribuir a aumentar el bienestar de su población local (Flores, 2008) centrándose en una prosperidad económica a largo plazo que permita valorar su nivel de competitividad.

Los autores, establecen que para entender la competitividad de un destino en el largo plazo es apropiado considerar dos elementos (Crouch \& Ritchie, 1999, p.142) las ventajas comparativas (recursos endógenos), que hacen referencia a los factores y patrimonio turístico (recursos) del destino, ya sean naturales o fruto de 


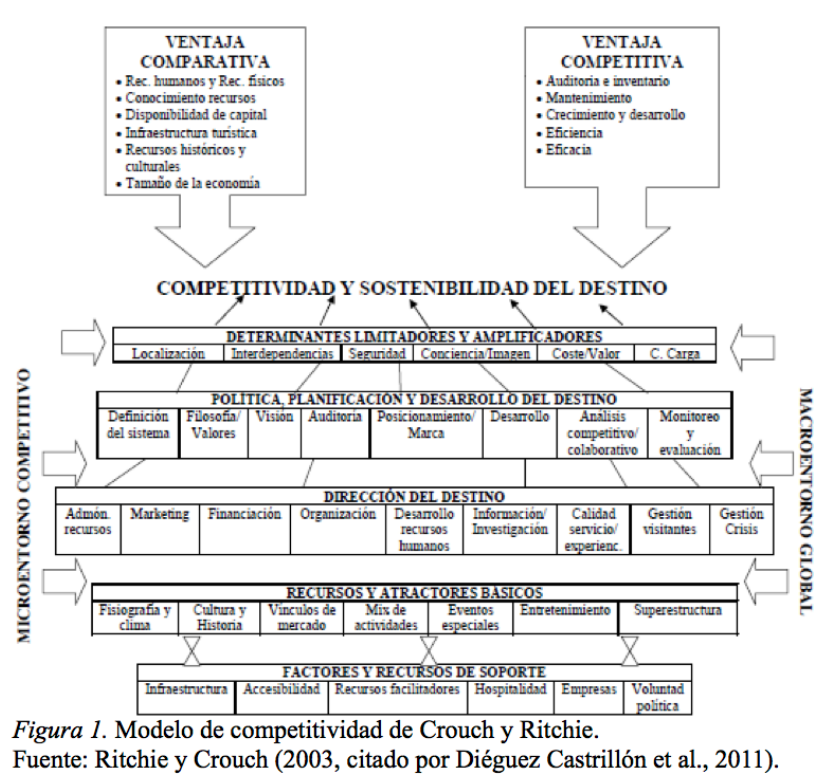

la acción humana (recursos humanos, recursos físicos, conocimiento de los recursos, disponibilidad de capital, infraestructura turística, recursos históricos y culturales y tamaño de la economía) y las ventajas competitivas (recursos desplegados) que son aquellas estrategias implementadas paragestionar yutilizardichas ventajas comparativas de manera eficaz a largo plazo (auditoría e inventario, mantenimiento, crecimiento y desarrollo y eficiencia y eficacia). De allí, el hecho de que un destino cuente con importantes ventajas comparativas no es garantía de que sea competitivo; por el contrario, el destinoturístico puede contar con escasas ventajas comparativas y llegar a ser altamente competitivo, si tiene la capacidad de valorar sus fortalezas, aprovechamiento de sus recursos e identificar sus debilidades (Sánchez, 2006,p.6).

Ritchie y Crouch (1999) consideran que la competitividad del sistema turístico está condicionado tanto por el entorno competitivo (micro) como por el entorno global (macro). Contemplan la existencia de una política de planificación y desarrollo del destino, así como de factores determinantes limitadores y/o amplificadores que influyen en la competitividad. El modelo conceptual no es un modelo "predictivo ni causal", sino únicamente explicativo. Que debe considerar permanentemente el carácter cambiante y evolutivo de los entornos que involucra, para ajustarlos a las exigencias de la realidad. Sin embargo, los aspectos del modelo de Crouch y Ritchie son de gran ayuda para diagnosticar y desarrollar estrategias para el mejoramiento de los destinos (Ritchie \& Crouch, 2003, p.62).

\section{Metodología}

Inicialmente se aborda una revisión bibliográfica que asocian las variables determinantes en la medición de competitividad de los destinos turísticos. Una vez estudiados se elige el modelo de competitividad turística de Crouch y Ritchie como referente para diagnosticar el destino. Posteriormente, los hallazgos reflejan un enfoque cuantitativo, de características descriptivas de orden propositivo, en la cual se caracteriza de acuerdo a las variables del modelo en mención.

El diseño de la investigación fue de tipo no experimental de corte transversal, debido a que no se tiene un grupo de control que compare a la población objetivo, además de recolectaron datos cuantificables, mediante una encuesta aplicada a las empresas turísticas del Golfo en un periodo de tiempo determinado. Para caracterizar a las empresas de la industria turística en el golfo de Morrosquillo, se hará uso del Muestreo Aleatorio Simple y se determinará un tamaño de muestra (n) basados en la proporción de empresas de la industria turística que consideran que hay talento humano calificado para la prestación de un excelente servicio(๘); el número de empresas seleccionadas es 86 de la industria turística del Golfo de Morrosquillo como población de interés.

\section{Resultados}

Como datos generales, la actividad principal del negocio turístico el estudio arroja que la mayor proporción de las empresas de la industria turística concentran su actividad en el alojamiento con un $69,8 \%$, los dedicados principalmente al servicio de restaurante son el 23,3\%, al servicio de transporte corresponde un $5,8 \%$ y en menor proporción un 1,2\% para las agencias de viaje. De este tipo de empresas, el $97,7 \%$ tiene menos de 10 empleados formales y el $2,3 \%$ restante tiene entre 10 a 50 empleados. Lo que muestra de que en el Golfo del Morrosquillo en jurisdicción del departamento de 
Sucre se cuenta con un sector empresarial compuesto por micro y pequeñas empresas.

Adicionalmente, el 76,7\% de las empresas no se encuentran inscritas en asociaciones o gremios empresariales, mostrando una desarticulación entre el sector empresarial de la región e inexistencia de estructuras solidas de asociatividad. Solo el $14 \%$ se encuentran vinculados a la Asociación de empresarios turísticos del Golfo de Morrosquillo (ASETUR), la cual se encarga de defender los intereses y derechos de los empresarios ante los entes territoriales que tengan injerencia en las políticas turísticas de la región. Por su parte el 4,7\% están adscritos a la asociación hotelera y turística de Colombia, la cual busca fortalecer la competitividad del sector hotelero del Departamento de Sucre. En menor proporción el $1,2 \%$ se relaciona con las asociaciones Aguturimar (guías turísticos del rincón del mar), Asocambe (Asociación de jóvenes ambientales y afrodescendientes) y gremio de empresas de transportadores.

En cuanto al turista, solo el $22,1 \%$ de los encuestados manifiesta no conocer el perfil del turista que llega al destino. No obstante, se obtuvo que los turistas que prefieren el destino del Golfo de Morrosquillo son los nacionales con un 84,9\%; provenientes de todo el país, principalmente de ciudades como Medellín, Bogotá, Montería y Cundinamarca. Los turistas locales representando un $12,8 \%$ y el $2,3 \%$ para los internacionales, con arribos desde Francia y Estados Unidos. De acuerdo al estudio de fortalecimiento de la comisión regional de competitividad en 2014, el departamento de Sucre está recibiendo turistas de otras regiones de estratos 3 , 4 y 5. La mayoría vienen de Medellín ya que la llegada de turistas de Bogotá, Cali, Triángulo del Café y Santander ha disminuido en los últimos años. Aproximadamente, un $70 \%$ de los pasajeros que llegan al aeropuerto de Montería, hacen su arribo en Sucre o solo pasan a hacer alguna actividad. También hay un perfil de turista local del departamento de estratos 2,3 y 4 que prefiere quedarse en habitaciones de bajo coste pues su estadía la mayoría de las veces es dominical y de paso.

Además, la llegada de turistas extranjeros empieza a tomar fuerza en el departamento. En su mayoría, la llegada de turistas extranjeros es de Estados Unidos y de manera incipiente europeos, estos turistas a diferencia del turista tradicional mochilero que anteriormente llegaba a la región, buscan hoteles y cabañas de alta calidad y están dispuestos a pagar por paquetes complementarios y oferta de industria auxiliar de ocio de alta gama.

En la dimensión de recursos y atractores básicos del destino, en lo que respecta a las ofertas de atractivos el estudio muestra que el 94,2\% coincidió que los sitios de interés natural entre los que se mencionan reservas naturales, mar y playa es el principal atractivo en que se concentra el destino. Por el contrario, los centros históricos y culturales no fueron considerados en lo absoluto como oferta de atractivo turístico. A pesar de que no se observa un potencial en cuanto a turismo cultural, un $62,8 \%$ de los encuestados manifiestan conocer la historia cultural del destino. Sin embargo, es muy poca la realización de eventos especiales que impulsen el tema cultural de la región, solo sale a colación eventos de tipo cultural y religioso. Además, se indica que pueden ser elegidas como atractivo cultural del destino las actividades de ocio que reflejan el estilo de vida del Golfo con un 93\% de aceptación por parte de las empresas turísticas. Del mismo modo, pero en menor proporción son atractivo cultural las artesanías (19,8\%), la religión (14\%) y las tradiciones de la región (12,8\%).

Entre los vínculos de mercado más frecuente que llevan al turista a elegir el destino del Golfo de Morrosquillo, se tiene que el 84, $9 \%$ se inclina por vínculos personales, el $12,8 \%$ realiza su elección basado en vínculos empresariales y el 2,3\% restante lo hace por vínculos o necesidad profesional. Como actividades complementarias que puedan disfrutar los turistas durante su estadía, el 46,5\% de las empresas asegura ofrecer a sus turistas pasadías en otros lugares cercanos al territorio, el $7 \%$ y 3,5\% manifiestan ofrecer planes familiares y aventura extrema respectivamente; mientras que el $2,3 \%$ y el 1,2\% dice contar con paquetes de relajación y actividades ecológicas. Por otra parte, un porcentaje significativo del 39,5\% no contempla ninguno tipo de actividad.

En el estudio de caracterización, las empresas turísticas del Golfo de Morrosquillo no muestran robustez 
en la estructura de sus organizaciones, indicando que el $72,1 \%$ de las empresas no tienen definidos procedimientos que permitan dar soporte al desarrollo de la gestión turística. En lo que se refiere a infraestructura del destino, el Golfo cuenta $100 \%$ con vías de acceso terrestres; así mismo, un 95,3\% del total encuestado sostiene que el destino dispone de servicios de salud como clínicas y hospitales. Un 38,4\% coincide en que se tienen vías de acceso aéreas, ya que se encuentra un aeropuerto en el municipio de Santiago de Tolú. Y finalmente, solo un 7\% del total comparten la apreciación que se cuenta con servicios de transporte urbano. De acuerdo al estado de las vías de acceso terrestres se tiene que el 67,4\% dice que en términos generales las vías se encuentran en buen estado. Sin embargo, los encuestados sostuvieron que en el último año se presentaron muchos incidentes relacionados con la lucha por la no aceptación del nuevo peaje instalado entre los municipios de Santiago de Tolú y Coveñas, puesto que incrementa los costos en la movilidad de los turistas, lo que a su vez se refleja en la baja de la llegada de estos al destino.

En las diferentes empresas de la industria turística se cuenta con servicios básicos principalmente redes eléctricas, suministro de gas y acueducto; el servicio de alcantarillado está disponible para el $43 \%$ de las empresas, específicamente en los ubicados en los límites de los municipios de Santiago de Tolú y Coveñas. Por otra parte, solo un $14 \%$ de los encuestados tiene redes telefónicas y un $37,2 \%$ del total cuenta con acceso a internet. Del mismo modo, el tipo de tecnología utilizada como apoyo para la prestación del servicio con un 58,1\% de elección se tienen las reservaciones con aplicaciones para celular o tablets; por su parte, un 27,9\% del total manifiesta no tener entre sus herramientas apoyo de tecnología. De los canales de comercialización como facilitadores del desarrollo de las actividades turísticas del territorio, el 38,4\% del total de encuestados asegura no tener ningún tipo de canal de comercialización; así mismo, un 22,1\% utiliza agencias de publicidad, un $3,5 \%$ recurren a instituciones financieras que facilitan la financiación a través de tarjetas de crédito, cheques de viaje, cambios de divisas, entre otros.

Otros pocos utilizan compañías de seguros $(2,3 \%)$ y consultores de investigación de mercado (1,2\%). Como variable relevante en la gestión turística de un destino, en cuanto al buen servicio al turista el estudio arroja que las empresas si realizan jornadas de sensibilización a sus empleados en temas relacionados con hospitalidad, amabilidad y cortesía en el servicio, representando un $91,9 \%$. Por otro lado, el tema de alianzas estratégicas con otros prestadores de servicios turísticos para el desarrollo de actividades complementarias e industrias de apoyo a su cadena de valor, el 70,9\% indica no tener ningún tipo de alianza. Es por ello, que un $94,2 \%$ de las empresas turísticos no consideran ningún producto y/o servicio complementario al ofrecido por el negocio, solo el 2,3\% menciona al teatro y música, y el 1,2\% dicen que la industria de apoyo a la actividad turística está en los centros comerciales, viajes a islas y concurrencia a parques ecológicos y temáticos.

Las empresas turísticas del Golfo, un 75,6\% concuerdan en que no desarrollan ningún tipo de productos o servicios a partir de los recursos turísticos del entorno; sin embargo, un $17,4 \%$ desarrolla paquetes especiales de actividades turísticas, un 11,6\% dispone de rutas por destinos especializados y un $1,2 \%$ del total estructura paquetes de relajación para ofrecer un mejor servicio a los turistas.

Por otra parte, se observa una debilidad en la relación entre las entidades territoriales y el sector privado, pues el $54,7 \%$ considera que la relación está en un nivel regular, el $36 \%$ asegura que es completamente mala y el 9,3\% cree en una relación buena entre estas figuras. Continuando con la gobernanza en el destino, para un 88,4\% desde la voluntad política no se están desarrollando estrategias que beneficien a las comunidades a partir del turismo. No obstante, el poco apoyo por parte del gobierno esta direccionado de acuerdo al $7 \%$ de los empresas turísticos en iniciativas enfocadas en el fortalecimiento de la capacidad empresarial y el espíritu de individuos y empresas, el 4,7\% indica que se promueven iniciativas por el desarrollo hotelero, buscando fomentar y facilitar la capacidad para recibir a los turistas; el 2,3\% mención las iniciativas de desarrollo y apoyo de trayectorias profesionales para los miembros de la industria turística local, por medio de la realización de talleres y charlas a la comunidad y el $1,2 \%$ expresa que 
las iniciativas no están dirigidas a apoyar pequeños negocios.

Para definir directrices en la dirección del destino, es importante conocer que atrae a los turistas al territorio, es de este modo, como las empresas turísticas identifican que el 74,4\% eligen el golfo principalmente para disfrutar de su mar, sol y playa; el 14\% dice que lo atraen los activos naturales conservados con los que cuenta, como bosques, mares, ciénagas y arroyos. Mientras que un 4,7\% hace su elección motivado por la herencia cultural y ancestral, sobre todo en el municipio de Santiago de tolú en épocas de semana por sus creencias religiosas.
Por otra parte, otros turistas representando el 3,5\%, el $2,3 \%$ y el $1,2 \%$ los atrae los parques naturales, la oferta de artesanías, música y danzas de la región y la presencia de sitios históricos respectivamente. Adicional a los atractivos del destino, las empresas turísticas enfocan la gestión de los recursos en dimensiones sustentables, en el Golfo de Morrosquillo el 39,5\% centra su buena gestión en los impactos en el ambiente natural, el 29,1\% en los impactos sobre el entorno construido, el 17,4\% toma a consideración los impactos sobre el entorno cultural y el 14\% restante simplemente no sabe hacia a que esta direccionada la gestión turística desde su organización. Además, en cuanto a la cooperación entre las empresas del destino, el $86 \%$ asegura que no existe articulación y apoyo para aunar esfuerzos que garanticen la integridad física y ecológica del golfo. Es así, como es evidente el trabajo desarticulado de los gremios que debilitan la competitividad turística de la región.

Por otra parte, el 41,9\% del total de las empresas de la industria turística no utilizan canales de comercialización que actúen como intermediarios de marketing. De igual forma, cabe destacar que el 37,2\% utiliza redes sociales y un $22,1 \%$ realiza este tipo de estrategias de marketing apoyados en las agencias de viajes. En el tema de inversión extranjera, el estudio arroja que no se tiene conocimiento de inversionistas extranjeros en la industria turística del Golfo de Morrosquillo (69,8\%), esto indica que el destino es poco atractivo para la incursión de nuevos grupos hoteleros y de empresarios de la actividad turística.
De acuerdo a las experiencias que han tenido las empresas turísticas, manifiestan que el destino cuenta con personal calificado para la prestación de un excelente servicio, solo el 4,7\% dice que en la región no se cuenta con el personal necesario para cubrir la demanda. De igual forma, indican que en materia organizacional los empleados tienen un completo conocimiento y manejo de los procesos; el 59,3\% del capital humano tiene un nivel de competencia de secundaria, el 32,6\% se encuentra en un nivel de primaria y el $8,1 \%$ ha realizado estudios a un nivel técnico. Además, la mayoría de las empresas turísticas indican que el 84,9\% de sus empleados no tienen ningún nivel de inglés y solo el 15,1\% cuenta con un nivel básico del idioma universal. Este hecho es muestra de una gran deficiencia en el propósito de jalonar el destino a terrenos internacionales y de clase mundial. Sin embargo, a pesar de buscar impulsar la competitividad turística del destino, el gobierno no desarrollaprogramas deformación quepermitan fortalecer las competencias del capital humano de la región.

En su política de recursos de información el 29,1\% del total de las empresas maneja indicadores de comportamiento de mercado, el $17,4 \%$ no implementa ningún programa de información que permita retroalimentar la calidad del servicio. Del mismo modo, un $15,1 \%$ estudia la información que arroja el rendimiento del destino en cuanto a los ingresos de las llegadas de turistas. El 12,8\% analiza la relación con los principales grupos de interés; así como, el 9,3\% toma como insumo las quejas, reclamos y sugerencias realizadas por parte de los visitantes al Golfo. En menos proporción, solo un 5,8\% realiza un análisis de la competencia y el $1,2 \%$ tiene en cuenta los resultados de las investigaciones de mercado. No obstante, el 100\% de las empresas turísticas manifestaron no utilizar el indicador de llegadas de turistas como dimensión para el manejo correcto de los recursos de información.

En lo que respecta a la experiencia del turista a partir del servicio ofrecido, esta se concentra un $36 \%$ en tranquilidad de mente, seguridad y confort; un $32,6 \%$ se centra en una experiencia hedónica que refleja la necesidad o el deseo de los turistas de hacer lo que les gusta. Por otra parte, el 30,2\% indica que el servicio ofrecido se engloba en una esfera de cooperación y el 1,2\% 
considera que no existe ninguna relación con este tipo de experiencias.

Es importante resaltar, que el $15,3 \%$ de las empresas tiene en cuenta la publicidad y promoción para minimizar los impactos negativos que han podido generarse durante la visita de los turistas; de la misma forma, el $44,2 \%$ se concentra en brindar y estar al pendiente de los detalles de una excelente atención, el 26,7\% utiliza el servicio de reservas antes de la visita, logrando facilitarle a turista los tramites a la hora de organizar sus viajes. Y un 15,1\% del total se preocupan por contar con precios diferenciales que se vuelvan atractivos al elegir el destino turístico. Para la gestión del riesgo en la dirección adecuada del destino, las empresas turísticas, exactamente el 81,4\% dice no contar con un programa para prevenir, controlar y mitigar los riesgos. En concordancia con lo anterior, el 91,9\% asegura no haber tenido ninguno tipo de riesgo durante la existencia de la empresa; sin embargo, el 3,5\% dice haber vivido una crisis económica mediante huelgas, escasez de trabajo y caídas de mercado, al igual y en la misma proporción las empresas han experimentado una crisis física por perdida y daños en equipos o fábricas. Por último, el $1,2 \%$ ha pasado por una crisis resultante de psicopáticos como secuestros, terrorismo, violencia, incendios y explosiones.

Desde la gestión del gremio empresarial del Golfo de Morrosquillo, no se evidencia una estructura sólida deplaneación estratégica que marque la ruta de trabajo hacia el fortalecimiento del destino a nivel competitivo, el 67,4\% no realiza actividades de definición y difusión del planes y mucho menos se logra la interiorización de la visión y misión de la empresa por parte de sus empleados, solo el 32,6\% manifestó que cuenta muy mínimamente con la definición de una estructura estratégica básica que se encuentra en los archivos de la empresa.

Adicionalmente, desde las tareas internas que debe cumplir la empresa para consolidarse y fortalecer la competitividad del destino, el estudio arroja que el $67,4 \%$ del total de empresas determina el presupuesto requerido, el $30,2 \%$ ha definido los procedimientos administrativos de la organización, el 19,8\% cuenta con estatutos definidos que dan mayor directriz a las iniciativas, así como el 3,5\% cumple con la determinación de las estructuras de los comités y el 10,5\% da importancia a las relaciones comunitarias, en las que se involucra los actores de la región. En el mismo sentido, como tareas externas las empresas turísticas manifiestan con múltiples respuestas que cumplen con los estándares de calidad de servicio (64\%), definición de estrategias de marketing (30,2\%). En la misma forma, tareas como rendición de cuentas $(17,4 \%)$ y la gestión de capital financiero y de riesgo (5,8\%). De igual forma, restándole importancia al tema de las proyecciones estratégicas, el 1,2\% de los encuestados tiene completo desconocimiento del significado de grupo de interés, el 24,4\% no toma a consideración a los grupos de interés para la toma de decisiones y aunque el $74,4 \%$ asegure que sí, se observa falta de compromiso para con la comunidad y los actores del sistema.

Sin embargo, como empresa perteneciente a la industria turística de Colombia, se obtuvo que enmarcan su política en el fortalecimiento de la infraestructura de servicios con un $36 \%$, en una proporción similar dirigen la política para asegurar la excelencia en la calidad del servicio con un $31,4 \%$. Mientras que las políticas para mantener y mejorar la integridad ambiental presentan un $15,1 \%$ de las apreciaciones y las políticas para preservar los atractivos naturales y el patrimonio cultural del destino un 17,4\%. Esto es muestra de las iniciativas del sector con respecto al mejoramiento en la calidad del servicio ofrecido a los turistas.

Además, de acuerdo a la información que tienen los administradores del gremio hotelero y de restaurantes, en los planes de desarrollo no se contempla ninguno tipo de inversión por parte del gobierno $(81,4 \%)$, solo algunos se atreven a decir que posiblemente se invierta en proyectos de infraestructura (10,5\%), que en el caso del municipio de tolú se están realizando adecuaciones en el parque central y algunas edificaciones. En el ámbito de educación como punto para fortalecer las capacidades destino es muy poca la apuesta $(1,2 \%)$, al igual que en lo social (7\%).

A pesar del poco respaldo que se tiene por parte de las unidades gubernamentales, las empresas turísticas 
coinciden en su mayoría que el Golfo tiene su fortaleza en los recursos turísticos lo que corresponde al 76,7\% de los encuestados. La otra proporción restante enfoca la fortaleza en la calidad en la atención. Este hecho de cierto modo muestra una sincronización por parte de los actores al identificar entre estos dos factores la ficha clave para apostarle y lograr la competitividad del territorio. En el mismo sentido, para lograr jalonar lo anterior, la visión debe estar enmarcada con un 39,5\% en un destino que valora y preserva la alta calidad y belleza del medio natural, con una proporción similar del 38,4\% este debe estar focalizado en un destino seguro, atractivo, limpio y eficiente; con un $18,6 \%$ se debe visionar un destino que refleja su diversidad cultural. Otros, por el contrario, consideran que se le debe apostar en un 2,3\% a un destino que prospera en todas las temporadas y es atractivo para los visitantes en todo momento y el 1,2\% tiende a una visión hacia un destino que valora y apoya el conocimiento y la educación.

Otro factor de gran importancia de esta dimensión es la percepción del destino que se busca reflejar en el mercado. De acuerdo al 59,3\% el Golfo tiene una percepción buena y no lo manifiestan muy convencido debido a las múltiples carencias que presenta el sistema. El 27,9\% dice que a nivel general es percibido como excelente, pero un 11,6\% lastimosamente sostiene que la percepción es regular, ya que hay muy poco interés de la inversión extranjera en el territorio. Además, lamentablemente para contrarrestar la baja percepción, no se realizan en el territorio actividades que potencialicen la identidad de marca del destino, lo cual es necesario para generar confianza y proyectar un destino de escala mundial.

En el ámbito de cooperación entre los actores, no se da mucha participación en proyectos para el desarrollo del destino, solo un 19,8\% dicen haber participado alguna vez en estrategias a nivel local, un $4,7 \%$ a nivel nacional y un 2,3\% con entes regionales; este tipo de estrategias no se han logrado debido a la inexistencia de una cultura de asociatividad, que de mayor fuerza al frente empresarial del destino y lo vuelva atractivo a la cooperación de cualquier otro destino. Aunque el bloque empresarial tiene mucha claridad en cuanto a las fortalezas del destino, si se cuestiona el conocimiento que tiene sobre el inventario de productos turísticos, se observa que es completamente nulo, pues desde la entidad gubernamental municipal no existe información al respecto, manifiestan que en el gobierno anterior se dio inicio al levantamiento del inventario, pero no se dejó registro sobre lo realizado.

Dentro de lo que se define como programa de mejora, las empresas principalmente se dedican al análisis de costos y resultados financieros (46,5\%), realizan auditorías contables - administrativas con una frecuencia anual (23,3\%), y otras se concentran en el sistema de atención de quejas, reclamaciones y sugerencias de los clientes (9,3\%), y en el análisis de los indicadores de gestión propios de la organización. Por su parte, un porcentaje significativo de las empresas ni siquiera consideran dentro de su administración la implementación de un programa de mejora. Como resultado de la materialización de la gestión turística, los empresarios exponen no haber realizado ninguno tipo de innovación en los últimos tres años; aunque algunos como el 36,1\% dice haber realizado innovación en producto, en procesosy en comercialización de servicios, se denota mucho desconocimiento desde las administraciones, de allí a que el $58,1 \%$ asegure no haber realizado ninguna de estas innovaciones.

Además, en la muestra seleccionada para el estudio no se encontró ninguna empresa que haya recibido reconocimiento nacional relacionado con la calidad del servicio. Una fuerza que jalona en gran medida la competitividad del destino son los componentes de esta dimensión. De este modo, para el 98,8\% de las empresas turísticos la localización del Golfo de Morrosquillo es muy favorable, a pesar de sus limitaciones en el acceso aéreo por la carencia de frecuencia de vuelos en el territorio, su ubicación es muy estratégica por su cercanía con destinos con mayor consolidación en el país.

En lo que respecta a la seguridad del destino, de acuerdo al 55,8\% de las empresas turísticas se maneja un nivel de seguridad modesto, el 39,5\% dicen que es alto y el 4,7\% comparte que en la región la seguridad es baja. Por otro lado, la percepción que se tiene por parte de los turistas está dividida casi en igual proporción, pues el $57 \%$ expresa que el destino es muy seguro y el 
$43 \%$ por su parte sostiene que es poco seguro. Discriminando por municipios se tiene una mejor percepción de seguridad en Coveñas, en donde el turista disfruta con más tranquilidad de los atractivos turísticos y de eventos nocturnos sin ningún problema, mientras que en el municipio de Santiago de Tolú se han presentado hechos de delincuencia común en los que se ha atentado contra la integridad del mismo. A pesar de que la imagen que se proyecta del destino ante el mercado objetivo es favorable y con altos niveles de conciencia, lo que corresponde al $81,4 \%$ de los encuestados. Se hace necesario la consolidación de una imagen del Golfo de Morrosquillo como destino turístico, pero la realidad entre los actores del sistema turístico no muestra el desarrollo de estrategias en pro de esta iniciativa.

De acuerdo al estudio, el costo del destino turístico está en un nivel medio con un $57 \%$, ya que se pueden encontrar hoteles a precios cómodos y para diferentes niveles de ingresos; otros como el 39,5\% dicen que es de nivel bajo y el 3,5\% creen que el costo es alto.

Por otra parte, se observa que para el $67,4 \%$ no existe relación de interdependencia con otro destino cercano, y para el 32,6\% se da una relación de sustituto y sinergia. Para el caso de la relación de sinergia, se convierte en una gran oportunidad para definir estrategias que fortalezcan la competitividad al complementarse entre las actividades turísticas que brindan. No obstante, a pesar de los limitantes y carencias del destino este tiene una capacidad de carga que está relacionada a ciertos factores. De acuerdo a la apreciación de los encuestados hay un desconocimiento alto en cuanto a los factores que se relacionan con la capacidad de carga con un $40,7 \%$; un $26,7 \%$ indica que la capacidad de alojamiento del bloque hotelero tiene gran incidencia, así como el 17,4\% dice que la accesibilidad y el 10,5\% la relaciona con los factores sociales de la región. Estos determinantes juegan un papel fundamental en el nivel de competitividad del destino, de ellos depende en gran medida lo atractivo que se vuelve el territorio para los turistas tanto locales, nacionales como internacionales.

\section{Conclusiones}

De acuerdo a los resultados obtenidos en la presente investigación, se puede concluir que el sector de turismo en el Golfo de Morrosquillo a pesar de las debilidades y problemáticas que presenta es un escenario de muchas oportunidades, que jalonaran la economía de la región generando un mayor dinamismo en la cadena de valor de la industria turística. Además, el estudio permitió evidenciar el compromiso por parte de los empresarios para fortalecer y mejorar el servicio ofrecidoy contar con las condiciones para competir a escala internacional.

En cuanto al análisis del macroambiente, el Golfo de Morrosquillo al igual que muchos otros destinos en Colombia está influenciado por todas las decisiones y estrategias implementadas a nivel nacional, las cuales deben ser analizadas por los operadores del destino para realizar con mayor efectividad su gestión y proyecciones de desarrollo. Entre las fuerzas del macroambiente cabe destacar la influencia de la fuerza económica con el comportamiento del dólar que determinada en gran medida la llegada de turistas internacionales. Así mismo, las fuerzas políticas son fundamentales, debido a que marcan la ruta para la participación de nuevos proyectos y muestran el respaldo de los entes gubernamentales para el desarrollo del sector.

En lo concerniente a la caracterización de las empresas de la industria turísticas del Golfo, la actividad turística se concentra principalmente en alojamiento, con una gran proporción en el municipio de Coveñas. Cuentan con un gran potencial en atractivos naturales, concentrando la oferta en el mar y la playa. Es de destacar que los vínculos de mercado más frecuente que llevan al turista a elegir el destino es el vínculo personal, por lo cual las actividades turísticas complementarias deben estar encaminada a ese tipo de intereses.

En cuanto a los factores y recursos soportes, existe mucha informalidad en las empresas, y las que existen no tienen una robustez organizacional, las estrategias en canales de comercialización y alianzas para promover un mayor número de visitantes son muy escasas, evidenciándose un nivel muy bajo de asociación y arti- 
culación con los demás actores dela cadena devalor. No cuenta con una infraestructura adecuada que contribuya abrindar una mejor experiencia al turista y las vías de acceso y servicios básicos están en malas condiciones.

En lo que respecta a la dirección del destino se tiene un capital humano con competencias muy básicas y la inversión en formación es muy poca. A pesar de las debilidades ya identificadas en los diagnósticos realizados para los planes de gobierno, los entes gubernamentales contemplan muy someramente el fortalecimiento de este sector, por lo que las iniciativas son muy escasas en cuanto a mejoramiento de condiciones y calidad en la prestación del servicio. De allí, a que el nivel de la planificación de las empresas turísticas no se evidencien estructuras solidas de planeación estratégicas y mucho menos políticas de marquen la ruta de trabajo para aumentar la competitividad que permita incursionar en escenarios de mayor exigencia.

Del mismo modo, los determinantes y amplificadores se encuentran en niveles no favorables como la imagen, la percepción en cuanto a seguridad y la capacidad de carga de las empresas. Este tipo de diagnóstico es muestra de las deficiencias que se tienen en un sector tan rico y lleno de oportunidades como lo es el turismo, para lo cual se debe implementar estrategias bien pensadas y articuladas de forma conjunta entre los actores del sistema, tomando como pilotaje la batería de empresas con las que se cuenta, que con apoyo y trabajo cooperativo lograrían jalonar esta industria y generar grandes impactos ybeneficios para el territorio.

Seguidamente, con el objetivo de determinar las variables claves el desarrollo competitivo de las empresas de la industria del turismo, se obtiene a través del análisis factorial que la estructura planteada por Crouch y Ritchie no aplica al entorno del Golfo de Morrosquillo, por ello la necesidad de plantear una nueva reagrupación y disminución mínima de las variables.

Finalmente, a partir de los resultados del análisis de factores, se plantea una ecuación matemática para medir el desarrollo de las empresas del sector en el Golfo basado en las variables claves, y con ello una nueva escala para la valoración de este. Además, será insumo para futuras investigaciones que permitan validar el instrumento y definir indicadores específicos para la competitividad turística en los municipios costeros en el Golfo de Morrosquillo del departamento de Sucre. 


\section{Referencias}

Crouch, G. I., \& Ritchie, J. R. B. (1999). Tourism, competitiveness, Crouch, G. I., \& Ritchie, J. R. B. (1999). Tourism, competitiveness, and societal prosperity. Journal of Business Research, 44(3), 137-152.

Del Río Cortina, J., \& Santisteben, R. D. F. (2011). Perspectivas del aprendizaje organizacional como catalizador de escenarios competitivos. Revista Ciencias Estratégicas, 19(26), 247-266.

Del Rio-Cortina, J., \& Blanquicett, O. (2009). Análisis cluster de los hoteles asociados a Asotelca y Cotelco de la ciudad de Cartagena de indias - Colombia. Turismo Y Desarrollo Local, 2(6).

Del Rio-Cortina, J., \& Pérez Correa, C. (2009). Estadios del conocimiento en el sector turístico de la ciudad Cartagena de indias. Turismo y desarrollo local, 2(6).

Del Rio-Cortina, J. L., Sepúlveda Chaverra, J. D., \& Meriño Stand, L. I. (2009). Propuesta de modelo de gestión estratégica en la filosofía empresarial en el sector turístico de la ciudad de Cartagena de indias. Turismo y desarrollo local, (6).

Del Rio-Cortina, J., \& Robledo-Fernández, J. C. (2014). La organización: innovación para la competitividad. Global Conference on Business and Finance Proceedings, 9(2), 2429.

Diéguez Castrillón, M. I., Gueimonde Canto, A., Sinde Cantorna, A. I., \& Blanco Cerradelo, L. (2011). Análisis de los principales modelos explicativos de la competitividad de los destinos turísticos en el marco de la sostenibilidad. CULTUR: Revista de Cultura E Turismo, 5(2), 101-124.

Dwyer, L., \& Kim, C. (2003). Destination Competitiveness: DeterminantsandIndicators.CurrentIssuesinTourism, 6(5), 369-414. https://doi.org/10.1080/13683500308667962

Flores Ruiz, D. (2007). Competitividad sostenible de los espacios naturales protegidos como destinos turísticos: Un análisis comparativo de los parques naturales Sierra de Aracena y picos de Aroche y Sierras de Cazorla, Segura y Las
Villas (Tesis de doctorado). Universidad de Huelva, Huelva, España.

Flores, D. (2008). Competitividad sostenible de los espacios naturales protegidos como destinos turísticos: Un análisis comparativo de los parques naturales Sierra de Aracena y picos de Aroche y Sierras de Cazorla, Segura y Las Villas (Tesis de doctorado). Universidad de Huelva, Huelva, España.

Mazaro, R. M., \& Varzin, G. (2008). Modelos de competitividad para destinos turísticos en el marco de la sostenibilidad. Revista de Administração Contemporânea, 12(3), 789-809. https://doi.org/10.1590/S1415-65552008000300009

Peinado, A. (2018). Propuesta de un plan estratégico logístico para una empresa de carácter social sin ánimo de lucro (Seccional Cali). Revista científica anfibios, 1(2), 60-68.

Poon, A. (1993). Tourism, technology and competitive strategies. Wallingford, Reino Unido: CAB international.

Porter, M. (1990). Competitive Advantage of Nations. Competitive Intelligence Review, 1(1), 14-14. https://doi. org/10.1002/cir.3880010112

Ritchie, J. R. B., \& Crouch, G. I. (2003). The competitive destination: A sustainable tourism perspective. Estados Unidos: CABI Publishing.

Rubio, J. (2018). Estrategias para brindar sustentabilidad a las líneas de comunicaciones marítimas a partir del crecimiento económico de Colombia 2010-2015: perspectiva rol de la ARC. Revista científica anfibios, 1(2), 53-59.

Sánchez, M. (2006). Elaboración de un ranking de competitividad de los destinos turísticos españoles: un análisis provincial mediante modelos de estructura latente. Revista de Análisis Turísticos, (1), 4-22.

Sarmiento, L. M. D. (2018). Gestión estratégica de proveedores para fortalecer el proceso de compras en la línea de negocios de reparación y mantenimiento de embarcaciones en COTECMAR. Revista científica anfibios, 1(2), 44-52. 


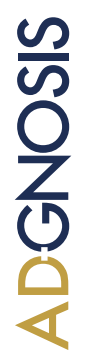

Valls, J. F. (2004). Gestión de destinos turísticos sostenibles. Barcelona, España: Grupo Planeta (GBS).

Palomeque, F., Marchena, M., Clavé, A., \& Vera, J. F. (1997). Análisis territorial del turismo: una nueva geografía del turismo. Madrid, España: Ariel

Vergara, F., Fernández, J. C. R., Prins, Z. A., \& Gutiérrez, G. C. (2019). Estrategias no convencionales de servicio: un desafío en el diseño organizacional. Revista científica anfibios, 2(1), 31-48. 